\title{
Expressive particle verbs and conditions on particle fronting ${ }^{1}$
}

\author{
ANDREAS TROTZKE \\ Stanford University \\ EVA WITTENBERG \\ University of California, San Diego
}

(Received 17 March 2015; revised 11 April 2016)

\begin{abstract}
In this paper, we propose a new distinction between expressive and non-expressive particle verbs in German. The basic observation for our proposal is that these two classes behave differently in the domain of particle fronting. In order to explain this difference, we will show that certain particle verbs are extreme degree expressions and that, therefore, a possible contrast across degrees makes fronting acceptable, even when the particle in isolation is non-contrastable. Our claims are supported by a rating study probing German native speakers' intuitions about the likelihood of the occurrence of an utterance, without relying on acceptability judgments. We connect these new findings to other forms of noninformation-structural fronting patterns that endow utterances with an emphatic flavor.
\end{abstract}

KEYWORDS: contrast, conventional implicatures, emphasis, extreme expressions, information structure, particle verbs

\section{INTRODUCTION}

In this paper, we argue for a distinction between expressive and non-expressive particle verbs in German (e.g. expressive rausschmeißen, i.e. raus + schmeißen, 'to fire someone/to kick someone out harshly' vs. non-expressive rausbringen, i.e. raus + bringen, 'to release something'). Our claim is based on evidence from fronting patterns of particle verbs. Specifically, we focus on fronting patterns involving non-contrastable verbal particles (such as in both rausschmeißen and rausbringen), that is, cases in which the particle cannot evoke a set of alternatives and thus cannot be interpreted in terms of information structure. We will account for the patterns we observe by testing the compatibility of certain particle verbs with degree modification that has proven useful to identify so-called extreme

[1] This article has benefited from discussion with Farrell Ackerman, Josef Bayer, Silvio Cruschina, Werner Frey, Joachim Jacobs, and Stefano Quaglia. We thank three anonymous $J L$ referees and Ewa Jaworska for their careful comments. We gratefully acknowledge financial support from the German Research Foundation (DFG grants BA 1178/9-1 and TR 1228/2-1) and from the DFG Excellence Initiative (University of Konstanz, project No. 610/14). 
adjectives (e.g. gorgeous or gigantic). We hypothesize that certain fronting patterns hinge on the expressive content of a particle verb construction, which means that a construction names a strongly emotionally evaluated situation. We will analyze this semantic component of particle verbs in terms of the degree semantics of extreme expressions. A rating study confirms our claim by providing empirical support both for the validity of our degree analysis and for our hypotheses regarding the different fronting behavior of expressive and non-expressive particle verbs.

The paper is structured as follows. In Section 2, we discuss general notions of non-information-structural fronting. Then, we turn to cases of particle fronting in the context of particle verb constructions. We establish a classification distinguishing between contrastable and non-contrastable verbal particles, and we argue that fronting of only the particle is licit in constructions where the particle can be contrasted, and illicit in constructions where the particle cannot be contrasted. However, we demonstrate certain exceptions to this pattern, i.e. we give examples where fronting of only the particle is possible although the particle is non-contrastable. In Section 3, we turn to these non-contrastable cases in more detail and distinguish between expressive and non-expressive particle verbs by connecting their syntactic behavior to established tests in degree semantics. Drawing on this distinction, we argue that the expressivity of certain particle verbs constrains fronting patterns, and that an information-structural explanation cannot account for the patterns we observe. In Section 4, we test our hypotheses experimentally by applying a novel rating procedure to expressive and nonexpressive particle verbs in either fronted or in situ position. Section 5 summarizes and concludes the paper.

\section{FRONTING PATTERNS BEYOND INFORMATION STRUCTURE}

\subsection{Emphatic fronting}

Traditionally, word order variation has been analyzed as reflecting facts about the information structure of utterances. ${ }^{2}$ However, recent analyses of the interpretation of word order variation have shown that certain instances of marked word orders are better analyzed as cases of expressing a speaker-related notion of emphasis, in addition to information-structural effects. For example, consider (1); full capitals here and in subsequent examples mark focal stress.

(1) Wie hat denn Steffi Graf im Turnier gespielt?

'How did Steffi Graf do in the tournament?'

(a) VERLOREN hat sie! lost has she

[2] For the purpose of this paper, we adopt the rather broad definition of information structure as the structuring of an utterance with respect to new and given information (in the sense of Halliday 1967). 
(b) Sie hat VERLOREN!

she has lost

'She lost.'

Verloren in both marked (1a) and unmarked word order (1b) expresses the information focus (Halliday 1967); however, (1a) adds some non-propositional information, in addition to answering the question: The marked order in (1a) emphasizes the fact that Steffi Graf lost a tennis tournament as remarkable and unexpected, provided that the common ground of speaker and hearer is that Steffi Graf, at the time of utterance, is the world's greatest tennis player. This is essentially the point of Frey (2010), who has argued that certain types of German marked word order yield an emphatic interpretation that cannot be analyzed by using common concepts of information structure; for example, (1a) conveys more than just marking propositional content as new or given.

Instead, the marked word order indicates to the listener that a non-canonical interpretation of the utterance is needed (Skopeteas \& Fanselow 2011, Bergen, Goodman \& Levy 2012). Specifically, since the relevant focus in the context given in (1) could also be realized in situ, as in (1b), the hearer expects that there is an additional non-canonical meaning conveyed by (1a). This inference procedure is a common assumption in the literature dealing with languages that allow such optionality (see Steube 2001 on German). But what is this non-canonical, additional meaning we observe in (1a), and in what sense does it go 'beyond' information structure? To address this issue, let us now turn to the interpretation of these constructions in detail.

If we assume that in these cases the emphatic effect is conventionally encoded by specific word orders, then we might analyze the meanings as conventional implicatures (CIs) in the sense of Potts (2007a), and not as conversational implicatures. Potts (2007a: 481) stresses that '[a]t the heart of the difference between the two classes of implicature lies the notion of deniability'. What is crucial here is deniability on the part of the speaker. As is well known, while conversational implicatures are a negotiable part of denotations in this sense, CIs are not. That is, their content cannot be denied by the speaker. Consider, for example, nominal appositives (an infamous axe murderer in (2a) below) and expressives (damn in (2b)); for other distinctive features of CIs, see Potts (2007a: $481-488) .^{3}$

(2) (a) Charlie, an infamous axe murderer, is at the door! (Potts 2012: 2517) (\#Charlie is not an infamous axe murderer.)

(b) The damn dog is on the couch.

(\#I like your dog.)

[3] The symbol \# indicates that the respective element/configuration is not licensed/is deviant in the particular semantic/pragmatic context intended by the given example. 
Given this distinction between CIs and other pragmatic effects, let us look at an example given by Frey (2010), where the special status of the referent in the prefield is expressed by a CI that is associated with this marked syntactic construction:

(3) Was hat Otto heute auf dem Markt gekauft?

(Frey 2010: 1424)

'What did Otto buy on the market today?'

(a) FLEISCH hat Otto heute gekauft, und 3 Pfund BaNAnen. meat has Otto today bought and 3 pounds bananas

'Today, Otto bought meat, and three pounds of bananas.'

(\#Aber dass er Fleisch gekauft hat, ist ja nicht weiter erwähnenswert/überraschend.)

(\#'However, the fact that he bought meat is not surprising/worth further mention.')

(b) Otto hat heute FLEISCH gekauft, und 3 Pfund BaNAnen.

Otto has today meat bought and 3 pounds bananas

'Today, Otto bought meat, and three pounds of bananas.'

The focus on Fleisch in (3a) is, according to Frey (2010), customarily interpreted as exhaustive. That is, following Grice's (1975: 45) maxim of quantity (i.e. the speaker should give a maximally informative answer), the hearer infers that the speaker asserts the complete subset of entities for which it is true that Otto bought them today on the market (meat in this case), and nothing else (Spector 2005). As both (3a) and (3b) show, the conversational implicature of exhaustivity can be cancelled out by adding the second conjunct (3 Pfund Bananen 'three pounds of bananas').

However, the implicature in (3a) - that the buying of meat is more remarkable/unexpected than the buying of bananas - cannot be cancelled by the speaker. Crucially, the speaker's remarkability ranking evoked by fronting Fleisch 'meat' results in a semantic ordering different from the ordering based on truthfulness. That is, the content related to the speaker's attitude in (3a) cannot be challenged, only the propositional content can. Of course, as one reviewer remarked, the speaker attitude alone can be challenged by another person, compare (3a) above with $\left(3 \mathrm{a}^{\prime}\right)$ below, the latter showing that we are dealing with a separable meaning component of the utterance here:

(3) $\left(a^{\prime}\right)$ A: Was hat Otto heute auf dem Markt gekauft?

'What did Otto buy on the market today?'

B: FLEISCH hat Otto heute gekauft, und 3 Pfund meat has Otto today bought and 3 pounds BaNAnen. bananas

'Today, Otto bought meat, and three pounds of bananas.'

A: OK, but what's so strange/surprising about Otto buying meat? 
For Sicilian, Cruschina (2012) adopts the term 'mirativity' from the typological literature (DeLancey 1997) to refer to the speaker's expression of surprise towards the proposition in (4b), as opposed to what he calls 'neutral focus' in (4a). This case parallels our example in (1) above, where the proposition that Steffi Graf lost a tennis match is rather unexpected to the speaker.

(4) Chi scrivisti?

(Cruschina 2012: 58)

'What did you write?'
(a) Scrissi
n'articulu.
write.PAST.1S an.article
(b) N'articulu scrissi!
an.article write.PAST.1S
'I wrote an article.'

Thus, the emphatic effect mentioned above for German also exists in Romance languages, and this type of fronting cannot (fully) be explained in terms of information-structural notions. Rather, these are non-propositional (non-at-issue) interpretative effects, which go beyond information structure and express the speaker's attitude towards the proposition. As the preceding examples indicate, there is some evidence that these effects could be analyzed as CIs in the sense of Potts (2007a). In fact, the interpretation of such fronting patterns exhibits further characteristics of CIs, such as the anti-backgrounding requirement. According to Potts (2007a: 485), CIs are distinguished from presuppositions in obeying 'an anti-backgrounding requirement: in cases where the content of a supplement is part of the initial context, the result is infelicity due to redundancy'. This can be illustrated by the following example:

(5) Lance Armstrong survived cancer.

(a) \#When reporters interview Lance, a cancer survivor, he often talks about the disease.

(b) And most riders know that Lance Armstrong is a cancer survivor.

While the redundancy expressed by (5b) causes no problem, a CI, here again expressed by a nominal appositive in (5a), results in infelicity, see Potts (2007a: 485).

Returning to our cases of emphatic fronting, we observe a similar pattern (see also Frey 2010: 1426). We argue that the redundancy of information conveyed by (i) the context and (ii) the CI-related fronting in (6) leads to infelicity:

(6) Context: Steffi Graf is expected to win the tournament.

A: Wie hat denn Steffi Graf im Turnier gespielt?

'How did Steffi Graf do in the tournament?'

B: \#GEWONNEN hat sie! won has she

'She won.' 
Given this general background on pragmatic inferencing, let us now present in more detail what we have in mind by using notions such as remarkability and mirativity. As soon as we refer to a 'remarkability ranking', we enter the semantic domain of evaluation. Crucially, '[i]dentifying evaluation .... is a question of identifying comparison, . . . evaluation consists of anything which is compared to, or contrasts with, the norm' (Hunston \& Thompson 2000: 13). In other words, the evaluative dimension of meaning always involves reference to a semantic ordering source ('the norm'). Specifically, the speaker expresses that there is at least one member of the set of alternatives that is more likely than the asserted one (e.g. more likely than the assertion in (1) that Steffi Graf lost a match). Note that the mirative effect in general could be analyzed in different ways. For instance, one could also make use of 'domain widening' in the sense of Zanuttini \& Portner's (2003) account of exclamatives. ${ }^{4}$ However, in what follows we adopt one possible approach in terms of comparative likelihood articulated by Bianchi (2015) and Bianchi, Bocci \& Cruschina (in press).

Turning to likelihood at the propositional level, the preceding discussion has shown that the choice of marked constructions such as VERLOREN hat sie (i.e. 'LOST has she' instead of Sie hat VERLOREN 'She has LOST', see above) is associated with an emphatic interpretation that can also be calculated in terms of likelihood. In formal semantics, the relative likelihood of propositions is based on both a relevant modal base and an ordering source that encodes the course of events in the world of evaluation, which in turn serves as the source of the speaker's general expectations (e.g. Grosz 2012, Kratzer 2012, Bianchi 2015). These two modal components for formalizing the notion of surprise/unexpectedness can be spelled out as (i) the modal base $f(\mathrm{w})$, i.e. a set of possible worlds which is accessible from the evaluation world $w$, and (ii) the ordering source $g(w)$, i.e. a set of propositions which imposes an ordering on the worlds of the modal base (see Kratzer 2012: 38-43).

Given these two modal components, we can define relations between propositions. As a first step, one can define the relation that a proposition $p$ is 'at least as good a possibility' as a proposition $q$ as follows (Kratzer 2012: 41):

$$
\text { (7) } \neg \exists u\left(u \in \cap f(\mathrm{w}) \& u \in q-p \& \forall v\left((v \in \cap f(\mathrm{w}) \& v \in p-q) \rightarrow u<_{g(\mathrm{w})} v\right)\right)
$$

The definition in (7) says that $p$ is at least as good a possibility as $q$ with respect to $f(\mathrm{w})$ and $g(\mathrm{w})$ iff there is no world $u$ in which $q$ is true and $p$ is false which is closer to the ideal provided by the ordering source $g(\mathrm{w})$ than all the worlds $v$ in which $p$ is true and $q$ is false. As for the notion of surprise/unexpectedness, we must then introduce the notion of 'better possibility' in order to account for the modal status of a proposition of being 'more likely'. In more formal terms, '[a]

[4] Note that the marked word order patterns discussed in this paper are not exclamatives, but rather sentence exclamations in the sense of Rett (2011). For instance, in contrast to exclamative cases, our fronting constructions additionally assert that $p$ and thus make a contribution to the discourse that could be denied or affirmed. 
proposition $p$ is a better possibility than a proposition $q$ in $w$ with respect to $f$ and $g$ iff $p$ is at least as good a possibility as $q$ with respect to $f$ and $g$, but the reverse does not hold' (Kratzer 2012: 41, emphasis in the original). ${ }^{5}$

Note that this modal analysis remains neutral as to what is regarded as a 'better possibility'. This is due to the neutrality towards the nature of the ordering source $(g(w))$; the nature of the ordering source would determine different sorts of modality relevant in concrete cases. If we assume that the emphatic effect mentioned above for examples such as VERLOREN hat sie can be captured in terms of surprise/unexpectedness and likelihood, respectively, then we would have to refer to a 'stereotypical ordering source' where a definition like the following applies: '[a] stereotypical conversational background is a function $f$ such that for any world $w, f(\mathrm{w})$ represents what is normal in $w$ according to some suitable normalcy standard for $w^{\prime}$ (Kratzer 2012: 37).

In what follows, we will see that this remarkability component can also be expressed by means of lexical semantics, and that fronting constructions need less extra context with lexical elements that entail an event that is remarkable as such. In addition, the evidence discussed in the following sections provides even stronger support for a notion of marked word order that goes beyond information-structural interpretations. Specifically, we turn to particle verbs where a fronted verbal element cannot evoke a set of alternatives. These cases raise the issue whether certain fronting patterns can be constrained by aspects other than information structure.

\subsection{Fronting patterns in particle verb constructions}

In particle verb constructions, the fronting of only the particle is a phenomenon that has been extensively discussed in the literature on present-day Germanic, including English (see Dehé 2015). As is the case for other Germanic languages, both semantic and structural factors have been claimed to constrain particle fronting in German (e.g. Stiebels \& Wunderlich 1994, Lüdeling 2001, Zeller 2001, S. Müller 2002). Most researchers agree that one major condition on particle fronting consists in the possibility of attributing a contrastive interpretation to the particle (e.g. McIntyre 2001: 44-45; Zeller 2001: 93; S. Müller 2002: 275). ${ }^{6}$ This explains why the sentence in (8) is grammatical, whereas the one in (9) is not.

[5] We refer to Bianchi et al. (in press) for a more detailed account that builds on the components introduced so far and extends the view of discourse context by Farkas \& Bruce (2010) to incorporate semantic ordering sources as a basis of evaluative commitments of the participants of a conversation.

[6] In this paper, we do not discuss the structural conditions/implementations of particle fronting because we are interested in bringing out the distinctness of a certain class of particle verbs on the basis of semantic and pragmatic considerations. For discussion of the type of movement and the phrasal status of verbal particles, see e.g. Wurmbrand (2000) and Zeller (2003); for a recent approach, see Trotzke \& Quaglia (in press). 
(8) ZU hat er die Tür gemacht (und nicht auf).

PART(close) has he the door made and not PART(open)

'He closed the door.'

(Zeller 2001: 89)

(9) *AUF hat Peter mit dem Trinken gehört.

PART has Peter with the drinking heard

'Peter stopped drinking.'

(Zeller 2001: 90)

While the fronted particle $z u$ in (8) may enter a relation of paradigmatic semantic opposition with the particle auf in auf-machen 'to open' (lit.: 'open-make'), the particle auf in auf-hören 'to stop' may not (compare \#zu-hören (lit.: 'to-hear'), \#ab-hören (lit.: 'off-hear'), etc. - here the respective forms are only licit in a different semantic context, i.e. within a different paradigm, compare e.g. zu-hören 'to listen' vs. weg-hören 'to not listen').

A recent study confirms this observation (Trotzke, Quaglia \& Wittenberg 2015). The study involved measuring acceptability judgments and investigated the contrast between cases such as (8) and (9) above. However, considering Trotzke et al.'s data pattern more closely, there is an indication that cases such as runtermachen 'to bash someone' (example (10) below) are more acceptable than cases such as aufhören 'to stop' (example (9)).
RUNTER hat sein Chef ihn vor
allen Kollegen gemacht!
PART(down) has his boss him in.front.of all colleagues made
'His boss bashed him in front of all his colleagues.'

Note that runtermachen parallels aufhören insofar as runter (like auf in aufhören, see above) cannot evoke a set of alternatives. Accordingly, both particle verbs involve non-contrastable verbal particles. However, while mean judgments in the Trotzke et al. study cited above for verbs such as aufhören were all at or below $20 \%$, runtermachen received a rating of above $40 \%$.

This effect is not predicted by the information-structural constraints mentioned above, according to which all particle verbs featuring non-contrastable verbal particles should behave alike. An obvious account in the case of runtermachen would be that found in Stiebels \& Wunderlich (1994), who argue that fronting of resultative or directional particles (like runter) improves the acceptability of such constructions (see also Webelhuth \& Ackerman 1999: 44-51 for related observations). In contrast to particles such as auf in aufhören, $r$-particles such as $r$-unter indicate a direction and can thus often be used (with the same relevant reading) in constructions with predication verbs; for instance, Er ist total runter (mit den Nerven) $=$ the result of being bashed ('He is totally down'; mit den Nerven, lit.: 'with the nerves', is an obligatory continuation in German) - compare *Er ist auf (mit dem Trinken), intended meaning: 'He is done with drinking'). It is thus argued that these directional particles accept fronting to a greater extent because they display a relatively high degree of semantic autonomy. We claim, however, that this is not the whole story. 
Observe the following minimal pair demonstrating differences between noncontrastable particles with a clear resultative/directional semantics:

(11) (a) RAUS hat der Chef den faulen Kerl geschmissen! PART(out) has the boss the lazy guy thrown

'The boss kicked the lazy guy out.'

(b) ??RAUS hat die Band ihr neues Album gebracht! PART(out) has the band their new album brought

'The band published their new album.'

In both cases, there is no semantic alternative to raus without referring to a different sense of the verb (compare \#reinschmeißen 'to throw in (e.g. the garbage)', \#reinbringen 'to bring in (e.g. the shopping)'). To be sure, in what follows we will argue that the resultative/directional component of the particles indeed plays a role. However, as the pair in (11) indicates, we will argue that this semantic aspect must be complemented by another semantic component to make particle fronting felicitous.

In the next section, we turn to these non-contrastable cases in more detail and distinguish between 'expressive' and 'non-expressive' particle verbs. Given this distinction, we will argue that only the expressive particle verbs (cases such as (11a) and (10)) allow fronting of non-contrastable particles.

\section{EXPRESSIVE AND NON-EXPRESSIVE PARTICLE VERBS}

\subsection{The lexical semantics of expressive particle verbs}

Let us turn to the cases given in (11) in more detail. While rausschmeißen entails that someone has been dismissed in a harsh way, rausbringen does not refer to any such intensity scale that could serve as a basis for expressing evaluation of the speaker: Either the band published or did not publish their album. The option of fronting the particle in (11a) seems to depend on the lexical aspect of the verb and its aspectual composition with degrees (Caudal \& Nicolas 2005). A first piece of evidence that suggests that the degree component is part of the lexical semantics of the relevant particle verbs mentioned above comes from the compatibility with wh-exclamatives featuring non-argumental wh-elements like was 'what' in (12).

$$
\begin{aligned}
& \text { Was sind die Fußballer verrückt! } \\
& \text { what are the soccer.players crazy } \\
& \text { 'How crazy the soccer players are!' }
\end{aligned}
$$

As (13) shows, this construction is incompatible with non-gradable predicates (such as verheiratet 'married' or tot 'dead'), see d'Avis (2013) for German.

$$
\begin{aligned}
& \text { ??Was sind die Großeltern tot! } \\
& \text { what are the grandparents dead }
\end{aligned}
$$

'How dead the grandparents are!' 
The pattern we observe in this context is that particle verbs are distinguished by either entailing or not entailing a degree component:

(14) (a) Was hat der Chef den Hans rausgeschmissen! what has the boss the Hans PART(out).thrown 'How the boss kicked out Hans!'

(b) Was hat sein Chef ihn runtergemacht! what has his boss him PART(down).made 'How his boss bashed him!'

(c) ??Was hat die Band ihr neues Album rausgebracht! what has the band their new album PART(out).brought 'How the band published their new album!'

What cases such as (14a) and (14b) have in common is that these particle verbs all name strongly emotionally evaluated situations ('to criticize someone heavily', 'to get rid of someone in a harsh way', etc.). In what follows, we will provide additional evidence that this extreme degree component is built in the lexical semantics of these particle verbs.

For the second piece of evidence, we turn to adjectival semantics. We observe that particle verbs such as rausschmeißen 'to fire someone/to kick someone out harshly' or runtermachen 'to bash someone' feature a particular scalar component in their lexical semantics that parallels semantic observations in the domain of socalled lexically extreme adjectives, e.g. gigantic or gorgeous. For instance, certain lexically extreme degree modifiers (e.g. downright or positively) can occur only with adjectives that can be analyzed as conveying 'extreme' content. This is shown by the contrast given in (15).

(15) (a) Your shoes are \{downright, positively $\}$ \{gigantic, gorgeous $\}$

(b) ??Your shoes are $\{$ downright, positively $\}\{$ big, pretty $\}$

(Morzycki 2012: 568)

An adjective like gorgeous is lexically extreme and thus can combine with a modifier such as downright very naturally (for such diagnostics, see Kennedy \& McNally 2005; and Rett 2011 for a comprehensive account of the relation between exclamative/expressive utterances and degree semantics). ${ }^{7}$ Interestingly, these

[7] It could be argued that this type of extreme degree modification also contributes to the 'expressive meaning dimension' in the sense of Potts (2007b). For instance, Morzycki (2012: 596-597) argues (on the basis of introspection) that expressives and extreme degree modifiers behave similarly with respect to their embeddability. However, Morzycki (2012) also provides evidence in favor of analyzing this type of modification as a form of presupposition - and not as conventional implicatures in the sense of Potts, see Schlenker (2007) for such an approach. We will stay neutral towards the issue of how to implement the effect of these modifiers at the semantics/pragmatics level. In fact, our data (just as Morzycki's discussion of extreme adjectives) has no bearing on the choice between these general approaches to expressive meaning components. 
adjectives resist an additional modification by very, as in e.g. *very gorgeous. This class of adjectives is thus often characterized as 'implicit superlatives' (Cruse 1986, Paradis 2001 and others), highlighting the fact that all individuals in their extensions are individuals who exceed their standard of comparison.

What is crucial in our context is the fact that we can apply the diagnostics used by Morzycki for detecting extreme content (in the sense sketched above) to certain particle verb constructions:

(16) (a) Der Chef hat den faulen Kerl regelrecht rausgeschmissen.

the boss has the lazy guy downright PART(out).thrown

'The boss kicked the lazy guy out.'

(b) ??Die Band hat ihr neues Album regelrecht rausgebracht. the band has their new album downright PART(out).brought

'The band published their new album.'

One can easily produce more minimal pairs (see our appendix) to demonstrate that particle verbs featuring non-contrastable verbal particles differ in their compatibility with extreme degree modifiers. Note that this also holds for particle verbs with so-called 'single' particles such as aus: aus in both (17a) and (17b) cannot be contrasted (e.g. *ein-flippen (lit.: 'in-freak') is non-existent; \#ein-gehen (lit.: 'in-go') is possible only within a different paradigm).

(17) (a) Ihre Schwester ist total ausgeflippt.

her sister is flat.out PART(out).freaked

'Her sister freaked out.'

(b) ??Hans ist heute Abend total ausgegangen.

Hans is today evening flat.out PART(out).went

'Hans went out tonight.'

In (16) and (17), we see that particle verbs featuring non-contrastable verbal particles differ in their compatibility with extreme degree modifiers such as regelrecht 'downright' or total 'flat out'. ${ }^{8}$ Note that these modifiers scope over the whole particle verb and cannot modify the particle alone.

Morzycki (2012: 597) points out that he adopts the presupposition view 'mostly for convenience, but it is consistent with the hypothesis . . . that expressive meaning in general is a form of presupposition'. Like Morzycki, we will abstract away from these bigger theoretical issues and merely focus on the extreme degree component of the expressions relevant for our paper.

[8] As is well known, these modification constraints operate across different grammatical categories. For instance, in addition to their applicability to adjectives and (particle) verbs, they can also be observed in the nominal domain:

(i) ??ein totaler Student

a flat.out student

(ii) ein totaler Idiot

a flat.out idiot 
Let us now turn to a third piece of evidence for the particular degree component of the relevant particle verbs: the naturalness of extreme items as a means of objecting to preceding discourse. Morzycki (2012) points out that extreme adjectives are especially good for raising an objection to something about the discourse. Consider the following examples from Morzycki (2012: 572-573):

(18) A: Clyde isn't particularly wealthy.

B: (a) No, he's (outright) destitute.

(b) \#Yes, he's (outright) destitute.

$\mathrm{B}^{\prime}$ : (a) \#No, he's very poor.

(b) Yes, he's very poor.

Although the reactions in $\mathrm{B}$ and $\mathrm{B}^{\prime}$ seem to convey the same propositional information, the use of an extreme adjective (destitute) in raising an objection sounds more felicitous than using a non-extreme adjective (poor) in this discourse context. The same holds for what we have called expressive and non-expressive particle verbs above:

(19) A: Der Chef hat Hans nicht gerade gut behandelt. the boss has Hans not really well treated 'The boss didn't really treat Hans well.'

B: (a) Wie meinst Du das? Er hat ihn (regelrecht) runtergemacht! 'How do you mean? He (downright) bashed him!'

(b) \#Wie meinst Du das? Er war (sehr) unfreundlich! 'How do you mean? He was (very) unfriendly!'

The cumulative evidence presented here suggests that we can analyze the lexical semantics of expressive particle verbs along the lines of analyses that have been proposed for extreme adjectives. In particular, we notice that expressive particle verbs operate on scales and that the manner of the event they denote either represents the ultimate (upper) point of a scale or goes even 'off the scale'. Building on Morzycki's analysis, we assume that the manner component of the verb semantics is based on a salient range of degrees $(=\mathrm{C})$. In the context of expressive particle verbs, this manner-related degree component $(=d)$ entails that the event denoted by the verb $(=\mathrm{e})$ features a manner component $(=\mathrm{m})$ that exceeds its standard of comparison. As is common in event semantics, we treat manner as one of many possible conceptual coordinates (e.g. Maienborn \& Schäfer 2011) and, in order to ensure that the manner component is linked to the specific conceptual properties of the event introduced by the respective verb, we use the underspecified relation $R$ (see Fodor 1972 and many others). The denotation of the particle verb rausschmeißen 'to fire someone/to kick someone out harshly' in (20b) includes the measure function $(\mu)$ given in (20a), see Portner $\&$ Rubinstein (in press) for a simplified formalism. 
(20) (a) $\mu_{\text {severity }}=[\lambda m: m$ has a severity . the degree $d$ such that $m$ measures $d$ in severity]

(b) $\llbracket$ rausschmeißen $_{\mathrm{C}} \rrbracket=\lambda y \lambda x \lambda e$ [DISMISS (e) \& AGENT (e, x) \& $\left.\operatorname{THEME}(\mathrm{e}, \mathrm{y}) \& \exists \mathrm{m}\left[\mathrm{R}(\mathrm{e}, \mathrm{m}) \& \exists \mathrm{d}\left[\mu_{\text {severity }}(\mathrm{m})=\mathrm{d} \wedge \mathrm{d} \geq \max (\mathrm{C})\right]\right]\right]$

Given this lexical distinction between expressive and non-expressive particle verbs, we can now turn to the question of fronting non-contrastable verbal particles.

\subsection{Fronting patterns of expressive particle verbs}

A natural account in terms of information structure would be to analyze configurations such as (11a), repeated here for convenience in (21) below, as 'pars-pro-toto constructions'. 9 That is, elements that do not fulfill any information-structural function in the left periphery alone can appear in the prefield 'pars pro toto', thereby highlighting the whole predicate.

(21) RAUS hat der Chef den faulen Kerl geschmissen!

PART(out) has the boss the lazy guy thrown

'The boss kicked the lazy guy out.'

This observation is well known in the literature on German (e.g. Jacobs 1991, Fanselow 2003). In particular, the category that appears in the left periphery of the German clause may be smaller than the focus (22) or larger than the focus (23a), and sometimes it coincides with the focus (23b), see Jacobs (1991: 8):

(22) Was hat er gemacht?

'What has he done?'

Ein BUCH hat er gelesen.

a book has he read

(23) (a) Was hat er gelesen?

'What did he read?'

Ein BUCH gelesen hat er.

a book read has he

(b) Ein BUCH hat er gelesen.

a book has he read

[9] In the literature, these constructions are referred to as cases of so-called 'pars-pro-toto movement' (Fanselow 2003). In this paper, we abstract away from theoretical issues such as the question if and how discourse features in general - including information-structural aspects - should be represented in the syntax and trigger movement (for discussion, see Trotzke 2015). Accordingly, we use the more neutral term 'pars-pro-toto construction'. 
At the level of information structure, preposing only a subpart of the focus (22) is equivalent to fronting the whole focal constituent, as in (24), which is a case of VP-fronting (see den Besten \& Webelhuth 1990 for the original discussion, and G. Müller 1998, 2004; Fanselow 2002 for different analyses).

(24) Was hat er gemacht?

'What has he done?'

Ein BUCH gelesen hat er.

a book read has he

Returning to our cases involving particle verbs, we observe that preposing only a subpart of the focus in $(11 \mathrm{a}, \mathrm{b})$, repeated here in $(25)$, is equivalent to fronting the whole focal constituent, as in (26):

(25) (a) RAUS hat der Chef den faulen Kerl geschmissen! PART(out) has the boss the lazy guy thrown

'The boss kicked the lazy guy out.'

(b) ??RAUS hat die Band ihr neues Album gebracht! PART(out) has the band their new album brought

'The band published their new album.'

(26) (a) RAUSgeschmissen hat der Chef den faulen Kerl!

PART(out).thrown has the boss the lazy guy

(b) RAUSgebracht hat die Band ihr neues Album! PART(out).brought has the band their new album

This equivalence at the level of information structure certainly holds between (25) and (26). However, this account cannot fully explain the difference we see in (25a) and (25b). We therefore hypothesize that what constrains fronting in these cases is the expressivity of the respective particle verbs, which in turn facilitates the mirative reading discussed in Section 2.1.

To be sure, one could imagine a context where (25b) is not that bad. For example, in a case where a band is known to spend many years in the studio before releasing a new album, the speaker might express his surprise about the fact that, this time, the publishing process has been completed very fast. However, in this case, as the scenario makes it very clear, the violation of the speaker's expectation is based on a very specific likelihood ranking (recall our discussion in Section 2.1 above) with regard to the speed of publishing of that particular band. In other words, the otherwise 'binary' option of publication (to either publish or not publish) is enriched by a degree dimension connected to the factor 'speed'. Crucially, verbs such as runtermachen 'to bash someone' and rausschmeißen 'to fire someone/to kick someone out harshly' entail a remarkability component (going beyond a certain degree threshold) which makes them felicitous in a fronting construction that is associated with the interpretation of unexpectedness on the part of the speaker. Verbs like rausbringen 'to release something', on 
the other hand, need a special context to be licensed in such an exclamatory fronting construction. Recall what we said above concerning the lexical semantics of particle verbs such as rausschmeißen. We said that their degree argument $(=\mathrm{d})$ is beyond a salient range $(=\mathrm{C})$, i.e. for all $\mathrm{d}^{\prime}$ in $\mathrm{C}, \mathrm{d}^{\prime}<\mathrm{d}$. Turning to the notions of remarkability and unexpectedness described in Section 2.1, we can now say that emphatic fronting serves to highlight that $d$ in the lexical semantics of expressive particle verbs is ranked as more remarkable as the alternatives $\mathrm{d}^{\prime}$ in $\mathrm{C}$, given a relevant semantic ordering source as discussed in Section 2.1. In other words, the unexpectedness component expressed by these constructions needs less extra context with verbs that lexically entail an event that is remarkable as such (i.e. involves the degree component sketched in Section 3.1 above).

As indicated by (16) and (17) above, we can use particles like $a b$, an, auf, aus, and $z u$ and particles like raus, rein, and runter to illustrate the extreme degree semantics of particle verbs. As is well known from the literature (McIntyre 2001, Zeller 2001), the former particle class is morphologically simple, while the latter is morphologically complex. McIntyre (2001) calls them 'single' and 'double' particles, respectively, see Table 1. Double particles consist of single particles and a functional morpheme (e.g. hin, her, or $r$ ) denoting directionality/resultativity of the particle (McIntyre 2001).

\begin{tabular}{lll}
\hline Single & Double & $\begin{array}{l}\text { English gloss } \\
\text { (single/double) }\end{array}$ \\
\hline ein & hin-ein, her-ein, r-ein & in/into \\
aus & hin-aus, her-aus, r-aus & out/out of \\
auf & hin-auf, her-auf, r-auf & on/on to \\
unter & hin-unter, her-unter, r-unter & under/down \\
an & her-an, r-an & on, next to/next to, closer to \\
weg & hin-weg & away/away \\
\hline
\end{tabular}

Table 1

Single vs. double particles in German (sample).

Note that this additional semantic component plays an important role in fronting verbal particles of expressive particle verbs. That is, the possibility of particle fronting seems less acceptable with verbs like ausflippen 'to freak out':

$$
\begin{array}{ll}
\text { ??AUS } & \text { ist ihre Schwester geflippt! } \\
\text { PART(out) is her sister freaked }
\end{array}
$$

Given that the German prefield (i.e. the phrasal position before the finite verb in main clauses) is usually quite liberal with respect to the moved phrase, it is reasonable to assume that the internal structural make-up of particles does not qualify as a convincing restriction on fronting possibilities (for an elaborate proposal of the internal make-up, see Noonan 2010 for German). 
Interestingly, single particles such as aus seem to be recalcitrant to fronting even when they contribute a clear spatial semantics. Consider the particle $a b$ 'off'. In the following minimal pair, the particle verbs $a b$-schicken 'to send off' and weg-schicken 'to send away' are synonyms: the single particles weg and $a b$ can be assigned quite similar denotations (see Stiebels 1996: 95). However, they clearly differ in the acceptability of constructions with the particle fronted to the prefield (see Kratzer 1994 for the original discussion):

$$
\begin{aligned}
& \text { (a) ??AB möchte ich das Manuskript (endlich) schicken! } \\
& \text { PART(off) want I the manuscript finally send } \\
& \text { (b) WEG möchte ich das Manuskript (endlich) schicken! } \\
& \text { PART(away) want I the manuscript finally send } \\
& \text { 'I want to send the manuscript away!' }
\end{aligned}
$$

Crucially, the particles do not exhibit the same degree of semantic autonomy. As (29) indicates, the resultative weg is semantically more autonomous than the particle $a b$ :
(a) *Das Manuskript ist ab. the manuscript is PART(off)
(b) Das Manuskript ist weg. the manuscript is PART(away)

We thus hypothesize that the presence of a semantically more autonomous particle in the prefield improves the acceptability of the resulting construction.

If true, the ameliorating role played by autonomy could be explained as a performance effect: The presence of a semantically highly autonomous item would qualify as a positive cue in the parsing of sentences where the particle is spelled out in the prefield and the lexical verb is not spelled out in an adjacent position (i.e. in the C-position). With autonomous particles, at least a part of the denotation of the VP can be established immediately, whereas non-autonomous particles would require the speaker to wait until reconstruction for the denotation of the whole VP to be derived (see Heine, Jacobs \& Külpmann 2010: 48-52 for discussion). This might suggest that not only information-structural contrast and expressivity of particle verbs are relevant in licensing the fronting of the particle, but also performance components connected to the semantic autonomy of the particle. In other words, in non-contrastable (i.e. non-information-structural) cases such as raus in rausschmeißen 'to (harshly) kick out'/rausbringen 'to release', and aus in ausflippen 'to freak out'/ausgehen 'to go out', only a combination of semantic autonomy of the particle and a possible contrast across degrees due to the expressivity of certain particle verbs makes fronting acceptable. In what follows, we report an empirical study that tested the claims formulated in the previous sections. 
4. TESTING THE DISTINCTION BETWEEN EXPRESSIVE AND NON-EXPRESSIVE PARTICLE VERBS

\subsection{Method and participants}

Against the background set out in Section 2 above, we wanted to create maximally natural out-of-the-blue contexts that pattern with the emphatic and mirative cases discussed in Section 2. Thus, we expanded a method first used by Trotzke et al. (2015): We told participants that they would be exposed to transcribed fragments (in the form of sentences) of a recorded conversation between two students, and that the transcription might not be entirely correct. The participants' task in the experiment was to assess for each sentence, using a 1-100 scale, how likely it was that we transcribed it correctly. These 'transcription ratings' served as our dependent variable. See (30) for an example with a verb form error and https:/github.com/ewittenberg/ExpressivePVs for complete instructions and materials.

$((02: 06))$

Julia: „Das Feuer bruch in der Scheune aus.“

('Julia: "The fire breaked in the barn out."')

Mit welcher Wahrscheinlichkeit haben wir das richtig transkribiert?

('How likely is it that we transcribed the utterance correctly?')

$0 \%$ $100 \%$

Preceding each example, the participants saw a random made-up time stamp (a number in double parentheses, minutes:seconds, as in the first line of (30) above). The time stamps were chronologically unordered, such that the creation of contextual coherence between the sentences was discouraged. In the text line below the utterance, we asked participants how likely it was that the transcription was correct, and they could make a guess by marking a point on a continuous line representing a scale from $0 \%$ to $100 \%$.

With this setup, we were able to make particle fronting felicitous without providing contrast categories, and we were able to avoid explicit judgments about grammaticality or acceptability, which are often correlated with each other, and also often influenced by prescriptive knowledge (see Myers 2009 for an overview and discussion). A follow-up question revealed that most participants were not aware of the true manipulation (only less than $10 \%$ of participants noted that the focus of the questionnaire might have been related to particles, degree modifiers, or word order).

We collected judgments from 80 native German speakers, all of them students at the University of Konstanz (70 female, average age: 21.8 years).

\subsection{Materials}

Our experimental sentences were manipulated at three levels: expressivity (in the sense of Section 3 above), word order, and the presence of a single or double 
particle. In each of the 12 sets of sentences, there was an expressive verb, such as rausschmeißen 'to (harshly) kick out', and a non-expressive counterpart, such as rausbringen 'to release'. For each of the verbs, we also varied word order, that is, whether the particle was in situ or fronted. Whenever the particle was in situ, the sentence also contained a degree modifier such as regelrecht 'downright' (see Morzycki 2012 and Section 3 above). Also, given our discussion in Section 3, half of the sets contained a single particle (like aus 'out') and half of them contained a double particle (like raus 'out/out of'). In total, there were 12 sets (three examples for every combination). A complete set of sentences with a single particle is given in (31) below and a complete set with a double particle is in (32); see our appendix for a full list of critical sentences.

(31) (a) Ihre Schwester ist total ausgeflippt.

her sister is flat.out PART(out).freaked

'Her sister freaked out.'

(b) Hans ist heute Abend total ausgegangen.

Hans is today evening flat.out PART(out).went

'Hans went out tonight.'

(c) Aus ist ihre Schwester geflippt.

PART(out) is her sister freaked

'Her sister freaked out.'

(d) Aus ist Hans heute Abend gegangen.

PART(out) is Hans today evening went

'Hans went out tonight.'

(32) (a) Der Chef hat den faulen Kerl regelrecht rausgeschmissen.

the boss has the lazy guy downright PART(out).thrown

'The boss kicked the lazy guy out.'

(b) Die Band hat ihr neues Album regelrecht rausgebracht. the band has their new album downright PART(out).brought 'The band published their new album.'

(c) Raus hat der Chef den faulen Kerl geschmissen. PART(out) has the boss the lazy guy thrown

'The boss kicked the lazy guy out.'

(d) Raus hat die Band ihr neues Album gebracht. PART(out) has the band their new album brought

'The band published their new album.'

To test whether our chosen degree modifiers replicate the acceptability behavior predicted by Morzycki (2012), we also created twelve sentences which contained the following three conditions: non-extreme (baseline) adjectives (e.g. The old house outside the city is small), baseline adjectives with a degree modifier 
(e.g. The daycare building will be downright big), and extreme adjectives with a degree modifier (e.g. The new train station is downright gigantic; see https://github.com/ewittenberg/ExpressivePVs for a full list of original German stimuli). According to Morzycki (2012), only sentences with bare baseline adjectives and extreme adjectives with degree modifiers should be acceptable; thus, we expected much lower transcription ratings for the combination of baseline adjectives with degree modifiers. In addition, we constructed ten fillers we expected to get high transcription ratings ('good' fillers), ten fillers we expected to get mixed transcription ratings ('medium' fillers, e.g. (33) below), and ten fillers we expected to get low transcription ratings ('bad' fillers, e.g. (30)).

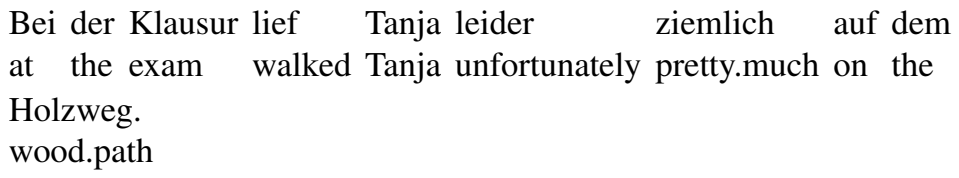

The medium and bad fillers were degraded for idiomatic or other semantic reasons (exchanging lexical items within an idiom in (33) or violating underspecification constraints), or for morphosyntactic reasons, containing tense or agreement errors, such as (30).

We counterbalanced lists such that each participant encountered both the expressive and the non-expressive verb in each set, but not in the same position, and only one instance of each verb. All participants saw items from each set. Thus, for each participant, there were 66 sentences in total. The utterances were presented in random order, starting with a filler.

\subsection{Results}

All data were analyzed using $\mathrm{R}$, specifically, the $\mathrm{R}$ packages lme4 and languageR (Baayen 2008, Bates, Maechler \& Bolker 2012). The particle verb data were analyzed by fitting a linear mixed-effects model with expressivity (expressive or non-expressive), particle type (double or single), and their interactions as fixed effects, and maximal random effects structures for items and participants (see Baayen, Davidson \& Bates 2008, Barr et al. 2013).

\subsubsection{Fillers}

As expected, transcription ratings for bad fillers were lowest (32.8\% (SD: 34\%)), transcription ratings for medium fillers were around chance (48.5\% (SD: $22 \%)$ ), and transcription ratings for good fillers were at ceiling (82\% (SD: 34\%)). This confirmed that our participants had understood the task and employed the full range of the scale for their judgments. The statistical analysis confirms that the differences were significant: Compared to bad fillers, medium fillers received 


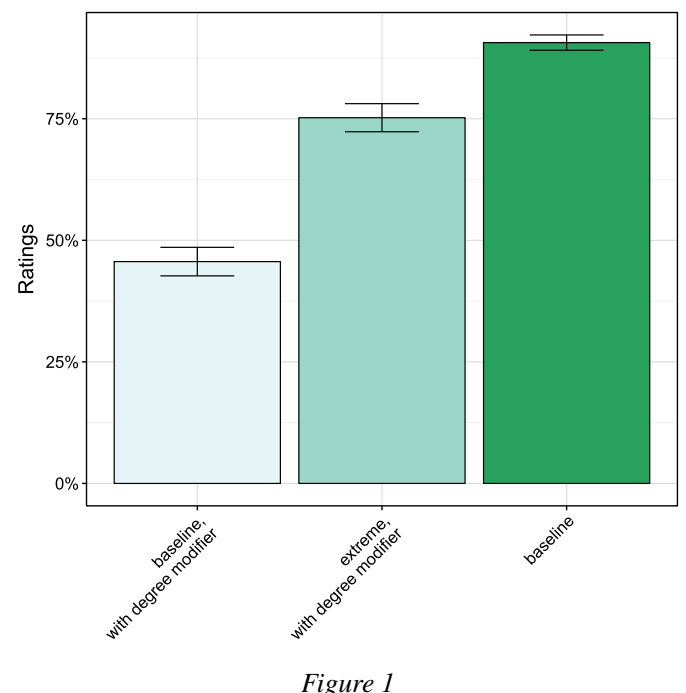

(Colour online) Transcription ratings of sentences containing either non-extreme adjectives with degree modifiers, extreme adjectives with degree modifiers, or non-extreme adjectives without modifiers (whiskers represent Standard Errors). All differences were significant.

higher transcription ratings $(\beta=0.49, t=28.8, p<.0001)$, and so did good fillers $(\beta=0.31, t=11.01, p<.0001)$.

\subsubsection{Adjective items}

Figure 1 shows transcription ratings for the adjective items, which were included to test Morzycki's (2012) claim (based on introspection) that degree modifiers are worse with non-extreme adjectives. We now provide empirical support for this claim: Accuracy of transcription was estimated to be lowest for sentences containing non-extreme adjectives with degree modifiers (45.6\% (SD: 27\%)), better (75.2\% (SD: 26\%)) for extreme adjectives with degree modifiers, and highest $(90.7 \%$ (SD: 14\%)) for baseline sentences that contained non-extreme adjectives and no modifiers. The statistical analysis confirms the visual impression: Sentences containing non-extreme adjectives with degree modifiers received lower transcription ratings than sentences with extreme adjectives with degree modifiers $(\beta=0.45, t=17.11, p<.0001)$, or the baseline sentences $(\beta=0.31$, $t=11.01, p<.0001)$.

\subsubsection{Particle verbs with degree modifiers}

As discussed in Section 3, we hypothesized that there are two classes of particle verbs (expressive and non-expressive), and that these two classes can be distinguished along the lines similar to those for distinguishing between extreme and 


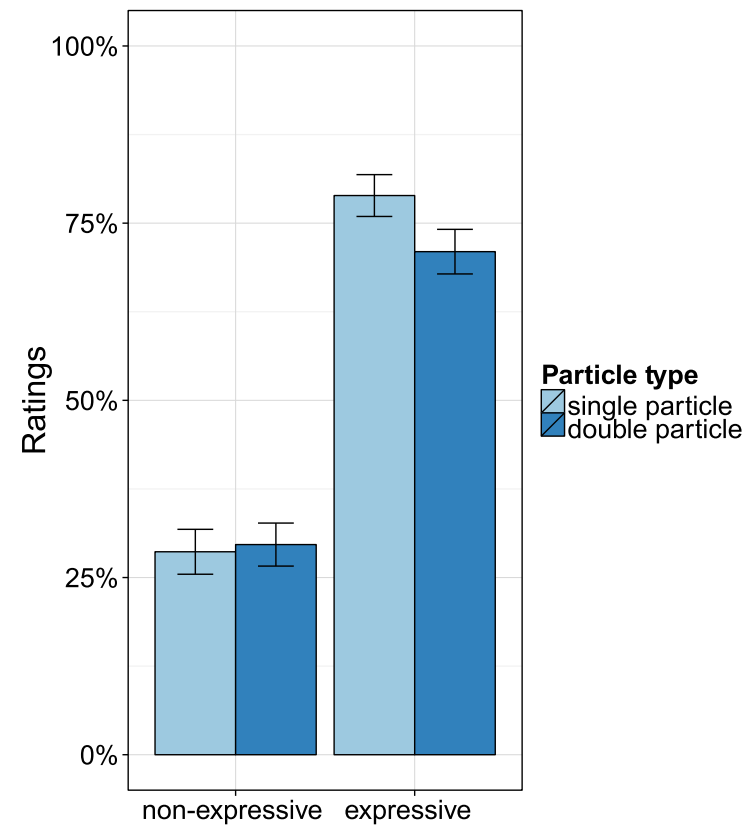

Figure 2

(Colour online) Transcription ratings of sentences containing either non-expressive particle verbs or expressive particle verbs in situ, with degree modifiers (whiskers represent Standard Errors). Expressiveness significantly influenced ratings, while the kind of particle (double or single) did not, and there was no significant interaction.

non-extreme adjectives. If this is true, then expressive particle verbs should be able to combine with degree modifiers such as regelrecht 'downright', total 'flat out', and geradezu 'utterly'.

Figure 2 shows the mean transcription ratings for sentences containing expressive and non-expressive particle verbs combined with degree modifiers in unmarked (in situ) position. Ratings for expressive particle verb sentences were indeed much higher than ratings for non-expressive particle verb sentences, confirming our hypothesis. The mean transcription rating for sentences with nonexpressive particle verbs was $29 \%$ (SD: $24 \%$ ), and the mean transcription rating for sentences with expressive particle verbs was $75 \%$ (SD: $25 \%$ ). This difference was significant, as indicated by a reliable influence of expressivity $(\beta=0.42, t=$ $7.73, p<.0001$ ). However, the kind of particle (single or double) did not influence the ratings $(\beta=-0.01, t=0.15, p>.87)$, and there was no reliable interaction between expressivity and particle type $(\beta=0.07, t=1.03, p>.3)$. Thus, it is indeed the case that there is a class of expressive particle verbs, and only verbs in this class can be combined with degree modifiers, regardless of particle type. 


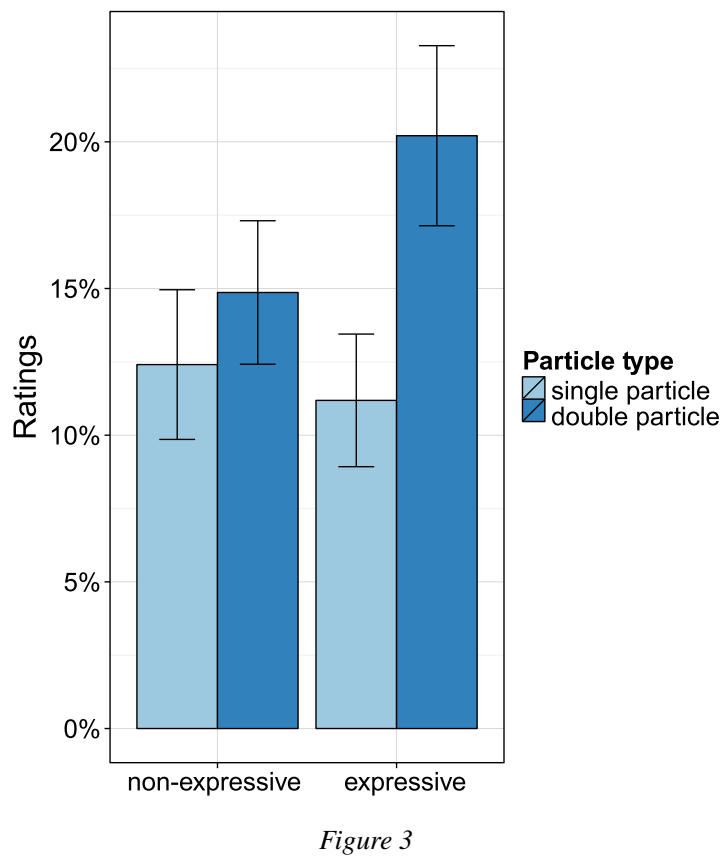

(Colour online) Transcription ratings of sentences containing either non-expressive particle verbs or expressive particle verbs in which the particles by themselves were fronted (whiskers represent Standard Errors). Expressiveness significantly influenced ratings, while the kind of particle (double or single) did not, but there was a significant interaction between expressivity and particle type.

\subsubsection{Particles in fronted position}

While the previous literature has claimed that fronting of an isolated noncontrastable particle is unacceptable, we set out to test whether this unacceptability can be modulated by the kind of particle. Given the discussion in Section 3, we hypothesize that sentences with double particles in expressive verbs were more acceptable than those with single particles - due to the directional meaning (and thus, as we argued, more autonomous semantics) of double particles. This impression has now been reliably confirmed.

Figure 3 shows the judgments for sentences in which the particles by themselves were fronted. As expected, the transcription ratings were low overall (between 11\% and 20\%), but fronted double particles in expressive verbs received transcription ratings that were between five and nine percentage points higher than the other particle-verb combinations.

This impression is confirmed by the statistical analysis. Overall, the expressive particle verbs received higher transcription ratings than the non-expressive particle verbs $(\beta=0.05, t=2.92, p<.003)$. While the particle type in itself did not influence ratings $(\beta=-0.02, t=-1.06, p>.28)$, the interaction of expressiveness and particle type was significant $(\beta=-0.07, t=-2.56, p<.02)$. 
Thus, again, expressive particle verbs received higher ratings than non-expressive particle verbs, but only when involving a double particle. This takes us back to our discussion in Section 3, where we argued that expressivity alone is not enough to allow non-contrastable verbal particles to be fronted - rather, this feature must be complemented by a resultative/directional semantics of the particle, yielding a certain semantic autonomy. The overall low level of acceptability might be due to the fact that the phenomenon of expressive particle fronting is particularly present in spontaneous language production and comprehension. Accordingly, although we avoided asking for explicit acceptability judgments by using the methodology described above, the metalinguistic character of the study might have influenced the ratings nevertheless.

\section{DISCUSSION AND CONCLUSIONS}

In this paper, we started from recent observations that certain forms of marked word order go beyond structuring an utterance into new or given information units. Instead, these emphatic forms of fronting mark propositional content as being surprising or unexpected to the speaker (Section 2). Strong support for such an interpretation of fronting comes from particle verbs with non-contrastable particles. Due to their status of being non-contrastable, the particles cannot evoke a set of alternatives. Consequently, their preposing can only be explained by a 'pars-pro-toto' interpretation at the level of information structure, according to which particle preposing is equivalent to expressing predicate focus by fronting the whole particle verb. However, recent empirical observations (e.g. Trotzke et al. 2015) show the limits of this approach, since not all particle verbs involving non-contrastable particles behave alike.

We account for this new empirical observation by distinguishing between expressive and non-expressive particle verbs. Due to their lexical semantics, expressive particle verbs behave differently from their non-expressive counterparts in the context of extreme degree modification (Section 3). Also, while fronting is still not preferred for particles in isolation, expressive particle verbs, which feature an extreme degree component, do better than non-expressive particle verbs because the possibility of establishing a possible contrast across degrees makes fronting acceptable, even when the particle in isolation is noncontrastable. Our analysis is supported by the results of a rating study (Section 4).

In this study, we avoided asking for explicit acceptability judgments, since they are often heavily influenced by prescriptive knowledge. In addition, we asked for ratings on a continuous scale rather than for categorical, discrete ratings. Participants needed to rate how likely it was that the sentences they saw were correctly transcribed from a fictitious audio recording. These 'transcription ratings' served as our dependent variable and allowed us to make the following observations.

First, our results confirm Morzycki's (2012) intuition that extreme degree modifiers are more compatible with extreme adjectives. Second, we could confirm empirically that there are two classes of particle verbs (expressive and 
non-expressive), because only expressive particle verbs can be combined with extreme degree modification. Third, we confirmed the hypothesis given in the literature that so-called double particles (such as raus 'out/out of', runter 'down', etc.), which usually express a resultative or directional semantics, can be fronted more easily than single particles (such as aus 'out', an 'at', etc.), which lack this semantic component. Given these observations, we see potential domains of future research, both at the formal-theoretical and at the psycholinguistic level.

As for theoretical issues, although we have solid knowledge about information structure (Krifka \& Musan 2012a) and the so-called expressive dimension of language (Potts 2012), the investigation of their similarities, differences, and interactions has only begun recently, as our sketch in Section 2 suggests. A crucial question is whether there are certain word orders (for example, certain fronting patterns) that feature non-propositional meaning components and that seem to be restricted by non-information-structural factors such as the degree semantics of elements involved in fronting operations. Our paper suggests that such interactions indeed exist.

As for work in psycholinguistics, the processing of information structure has become a fertile area of investigation (for recent overviews, see Skopeteas 2012, Arnold et al. 2013), while adopting and testing formal theories of expressive meaning components in language processing or computational modeling is a relatively new domain (e.g. Maas et al. 2011, Frazier, Dillon \& Clifton 2015). As we indicated in Sections 2 and 3, formal linguistics has forged excellent tools to approach this meaning dimension. A promising perspective for future collaboration and cross-fertilization is to connect these accounts to the psycholinguistic literature, especially within a Bayesian framework, which has proven to be a powerful tool to model discourse and processing expectations, and what their confirmation or violation says about underlying representation (Levy 2008, Rohde, Levy \& Kehler 2011, Rohde \& Kehler 2014, Xiang \& Kuperberg 2015).

Our example of unexpected word order, namely fronting only the particle of a particle verb construction, is surely violating processing expectations that vast experience with unmarked word order has created in speakers. Rating studies such as our paper and related work testing speakers' judgments can provide a promising starting point for a comprehensive understanding of how discourse categories such as surprise, mirativity, and unexpectedness are processed within the domain of natural language.

\section{APPENDIX}

\section{Stimuli: Critical sentences}

For a full list of stimuli, including fillers, see https://github.com/ewittenberg/ ExpressivePVs. We list each sentence with the particle (underlined) in situ and with the degree modifier in parentheses; when fronted, that particle is at the beginning of the sentence, i.e. Der Chef hat den faulen Kerl (regelrecht) rausgeschmissen $\rightarrow$ Raus hat der Chef den faulen Kerl geschmissen. 


\section{EXPRESSIVE}

1. rausschmeißen 'to kick out'

2. runtermachen 'to bash'

3. reinreißen 'to drag someone in'

4. ranschmeißen 'to throw oneself at someone'

5. rausfliegen 'to get thrown out'

6. reinziehen 'to guzzle'

7. ausflippen 'to freak out'

8. aufmotzen 'to doll oneself up'

9. abgehen 'to get carried away'

10. nachrennen 'to chase someone romantically'

11. absahnen 'to rake in'

12. einbrechen 'to fail'

\section{NON-EXPRESSIVE}

1. rausbringen 'to publish'
Der Chef hat den faulen Kerl regelrecht rausgeschmissen.

'The boss downright kicked the lazy guy out.' Der Lehrer hat die arme Lisa regelrecht runtergemacht.

'The teacher downright bashed poor Lisa.'

Fred hat Oskar in diese Angelegenheit ganz und gar reingerissen.

'Fred downright dragged Oscar into this thing.' Uwe hat sich an Maria total rangeschmissen.

'Uwe totally threw himself at Maria.'

Fritz ist aus seinem neuen Job regelrecht rausgeflogen.

'Fritz got downright thrown out of his new job.' Peter hat sich die vier Flaschen Bier geradezu reingezogen.

'Peter downright guzzled those four bottles of beer.'

Ihre Schwester ist total ausgeflippt.

'Her sister totally freaked out.' Katja hat sich regelrecht aufgemotzt.

'Katja downright dolled herself up.'

Karl und Frieda sind auf der Tanzfläche absolut abgegangen.

'Karl and Frieda got absolutely carried away on the dance floor.'

Sebastian ist seiner Exfreundin monatelang regelrecht nachgerannt.

'Sebastian downright chased his ex-girlfriend for months.'

Thomas hat bei der letzten Runde Poker absolut abgesahnt.

'Thomas absolutely raked in the cash in the last round of poker.'

Stefan ist bei der Prüfung völlig eingebrochen.

'Stefan totally failed at the exam.'

Die Band hat ihr neues Album regelrecht rausgebracht.

'The band downright released their new album.' 
2. runterschlucken

'to swallow'

3. reinschreiben

'to write something into something'

4. ranschreiben

'to write something onto something'

5. rausstellen

'to make clear'

6. reinstecken

'to insert'

7. ausgehen

'to go out'

8. aufnehmen

'to record'

9. abgeben

'to cede something'

10. nachschauen

'to look something up'

11. abholen

'to pick someone up'

12. einbringen

'to contribute'

Max hat das Kaugummi regelrecht

runtergeschluckt.

'Max downright swallowed the chewing gum.'

Susi hat in das Poesiealbum ganz und gar

reingeschrieben.

'Susi downright wrote something into the friendship book.'

Der Professor hat seine Lösung an die Tafel total rangeschrieben.

'The professor totally wrote the solution on the board.'

Der Forscher hat das Problem noch einmal regelrecht rausgestellt.

'The researcher downright made clear the problem again.'

Der Handwerker hat den Schlüssel ins Schloss geradezu reingesteckt.

'The handyman downright inserted the key into the lock.'

Hans ist heute Abend total ausgegangen.

'Hans totally went out tonight.'

Anna hat sich mit ihrem neuen Mikrofon regelrecht aufgenommen.

'Anna downright recorded herself with her new microphone.'

Die Ministerin hat den Posten absolut abgegeben.

'The secretary absolutely ceded her post.'

Der Schüler hat in seinem Lexikon regelrecht nachgeschaut.

'The student downright looked something up in his lexicon.'

Markus hat seine Freundin absolut abgeholt.

'Markus absolutely picked his girlfriend up.'

Der Politiker hat das Thema in die Diskussion völlig eingebracht.

'The politician completely contributed the topic to the discussion.'

\section{REFERENCES}

Arnold, Jennifer E., Elsi Kaiser, Jason M. Kahn \& Lucy K. Kim. 2013. Information structure: Linguistic, cognitive, and processing approaches. WIREs Cognitive Science 4, 403-413.

Baayen, R. Harald. 2008. Analyzing linguistic data: A practical introduction to statistics using $R$. Cambridge: Cambridge University Press. 
Baayen, R. Harald, Doug Davidson \& Douglas Bates. 2008. Mixed-effects modeling with crossed random effects for subjects and items. Journal of Memory and Language 59, 390-412.

Barr, Dale J., Roger Levy, Christoph Scheepers \& Harry J. Tily. 2013. Random effects structure for confirmatory hypothesis testing: Keep it maximal. Journal of Memory and Language 68, 255-278.

Bates, Douglas, Martin Maechler \& Ben Bolker. 2012. Ime4: Linear mixed-effects models using S4 classes. Retrieved from http://cran.r-project.org/package=lme4 (R package version 0.999999-0).

Bergen, Leon, Noah D. Goodman \& Roger Levy. 2012. That's what she (could have) said: How alternative utterances affect language use. Proceedings of the 34th Annual Conference of the Cognitive Science Society, 120-125.

Bianchi, Valentina. 2015. Focus fronting and the syntax-semantics interface. In Ur Shlonsky (ed.), Beyond functional sequence, 60-72. Oxford: Oxford University Press.

Bianchi, Valentina, Giuliano Bocci \& Silvio Cruschina. in press. Focus fronting, unexpectedness, and evaluative implicatures. Semantics \& Pragmatics.

Caudal, Patrick \& David Nicolas. 2005. Types of degrees and types of event structures. In Claudia Maienborn \& Angelika Wöllstein (eds.), Event arguments: Foundations and applications, 277-300. Berlin: Mouton de Gruyter.

Cruschina, Silvio. 2012. Discourse-related features and functional projections. Oxford: Oxford University Press.

Cruse, D. A. 1986. Lexical semantics. Cambridge: Cambridge University Press.

d'Avis, Franz. 2013. Exklamativsatz. In Jörg Meibauer, Markus Steinbach \& Hans Altmann (eds.), Satztypen des Deutschen, 171-201. Berlin: Mouton de Gruyter.

Dehé, Nicole. 2015. Particle verbs in Germanic. In Peter O. Müller, Ingeborg Ohnheiser, Susan Olsen \& Franz Rainer (eds.), Word formation: An international handbook of the languages of Europe, 611-626. Berlin: Mouton de Gruyter.

DeLancey, Scott. 1997. Mirativity: The grammatical marking of unexpected information. Linguistic Typology 1, 33-52.

den Besten, Hans \& Gert Webelhuth. 1990. Stranding. In Günther Grewendorf \& Wolfgang Sternefeld (eds.), Scrambling and barriers, 77-92. Amsterdam: John Benjamins.

Fanselow, Gisbert. 2002. Against remnant VP-movement. In Artemis Alexiadou, Elena Anagnostopoulou, Sjef Barbiers \& Hans-Martin Gärtner (eds.), Dimensions of movement: From features to remnants, 91-126. Amsterdam: John Benjamins.

Fanselow, Gisbert. 2003. Surprising specifiers and cyclic spellout. Generative Linguistics in Poland 5, $29-46$.

Farkas, Donka F. \& Kim B. Bruce. 2010. On reacting to assertions and polar questions. Journal of Semantics 27, 81-118.

Fodor, Jerry A. 1972. Troubles about actions. In Donald Davidson \& Gilbert Harman (eds.), Semantics of natural language, 48-69. Dordrecht: Reidel.

Frazier, Lyn, Brian Dillon \& Charles Clifton. 2015. A note on interpreting damn expressives: Transferring the blame. Language and Cognition 7, 291-304.

Frey, Werner. 2010. Ā-Movement and conventional implicatures: About the grammatical encoding of emphasis in German. Lingua 120, 1416-1435.

Grice, H. Paul. 1975. Logic and conversation. In Peter Cole \& Jerry L. Morgan (eds.), Speech acts (Syntax and Semantics 3), 41-58. New York: Academic Press.

Grosz, Patrick G. 2012. On the grammar of optative constructions. Amsterdam: John Benjamins.

Halliday, M. A. K. 1967. Notes on transitivity and theme in English: Part 2. Journal of Linguistics 3, 199-244.

Heine, Antje, Joachim Jacobs \& Robert Külpmann. 2010. Quer zu den Feldern: Zur Topologie von Partikelverben. Linguistische Berichte 221, 37-60.

Hunston, Susan \& Geoffrey Thompson. 2000. Evaluation in text: Authorial stance and the construction of discourse. Oxford: Oxford University Press.

Jacobs, Joachim. 1991. Focus ambiguities. Journal of Semantics 8, 1-36.

Kennedy, Christopher \& Louise McNally. 2005. Scale structure, degree modification, and the semantics of gradable predicates. Language 81, 345-381.

Kratzer, Angelika. 1994. The event argument and the semantics of voice. Ms. University of Massachusetts Amherst.

Kratzer, Angelika. 2012. Modals and conditionals: New and revised perspectives. Oxford: Oxford University Press.

Krifka, Manfred \& Renate Musan. 2012a. Information structure: Overview and linguistic issues. In Krifka \& Musan (eds.), 1-44. 
Krifka, Manfred \& Renate Musan (eds.). 2012b. The expression of information structure. Berlin: Mouton de Gruyter.

Levy, Roger. 2008. Expectation-based syntactic comprehension. Cognition 106, 1126-1177.

Lüdeling, Anke. 2001. On particle verbs and similar constructions in German. Stanford, CA: CSLI Publications.

Maas, Andrew L., Raymond E. Daly, Peter T. Pham, Dan Huang, Andrew Y. Ng \& Christopher Potts. 2011. Learning word vectors for sentiment analysis. Proceedings of the 49th Annual Meeting of the Association for Computational Linguistics, 142-150.

Maienborn, Claudia \& Martin Schäfer. 2011. Adverbs and adverbials. In Klaus von Heusinger, Claudia Maienborn \& Paul Portner (eds.), Semantics: An international handbook of natural language meaning, vol. 2, 1390-1420. Berlin: Mouton de Gruyter.

McIntyre, Andrew. 2001. German double particles as preverbs: Morphology and conceptual semantics. Tübingen: Stauffenburg.

Morzycki, Marcin. 2012. Adjectival extremeness: Degree modification and contextually restricted scales. Natural Language \& Linguistic Theory 30, 576-609.

Müller, Gereon. 1998. Incomplete category fronting. Dordrecht: Kluwer.

Müller, Gereon. 2004. Verb-second as vP-first. The Journal of Comparative Germanic Linguistics 7 , 179-234.

Müller, Stefan. 2002. Complex predicates: Verbal complexes, resultative constructions and particle verbs in German. Stanford, CA: CSLI Publications.

Myers, James. 2009. Syntactic judgment experiments. Language and Linguistics Compass 3, 406-423.

Noonan, Máire. 2010. Á to zu. In Guglielmo Cinque \& Luigi Rizzi (eds.), Mapping spatial PPs, 161-195. Oxford: Oxford University Press.

Paradis, Carita. 2001. Adjectives and boundedness. Cognitive Linguistics 12, 47-65.

Portner, Paul \& Aynat Rubinstein. in press. Extreme and non-extreme deontic modals. In Nate Charlow \& Matthew Chrisman (eds.), Deontic modality. Oxford: Oxford University Press.

Potts, Christopher. 2007a. Conventional implicatures: A distinguished class of meanings. In Gillian Ramchand \& Charles Reiss (eds.), The Oxford handbook of linguistic interfaces, 475-501. Oxford: Oxford University Press.

Potts, Christopher. 2007b. The expressive dimension. Theoretical Linguistics 33, 165-198.

Potts, Christopher. 2012. Conventional implicature and expressive content. In Claudia Maienborn, Klaus von Heusinger \& Paul Portner (eds.), Semantics: An international handbook of natural language meaning, vol. 3, 2516-2536. Berlin: Mouton de Gruyter.

Rett, Jessica. 2011. Exclamatives, degrees and speech acts. Linguistics and Philosophy 34, 411-442.

Rohde, Hannah \& Andrew Kehler. 2014. Grammatical and information-structural influences on pronoun production. Language, Cognition, and Neuroscience 29, 912-927.

Rohde, Hannah, Roger Levy \& Andrew Kehler. 2011. Anticipating explanations in relative clause processing. Cognition 118, 339-358.

Schlenker, Philippe. 2007. Expressive presuppositions. Theoretical Linguistics 33, 237-245.

Skopeteas, Stavros. 2012. The empirical investigation of information structure. In Krifka \& Musan (eds.), 216-246.

Skopeteas, Stavros \& Gisbert Fanselow. 2011. Focus and the exclusion of alternatives: On the interaction of syntactic structure with pragmatic inference. Lingua 121, 1693-1706.

Spector, Benjamin. 2005. Scalar implicatures: Exhaustivity and Gricean reasoning. In Maria Aloni, Alastair Butler \& Paul Dekker (eds.), Questions in dynamic semantics, 229-254. Leiden: Brill.

Steube, Anita. 2001. Correction by contrastive focus. Theoretical Linguistics 27, 215-249.

Stiebels, Barbara. 1996. Lexikalische Argumente und Adjunkte. Berlin: Akademie Verlag.

Stiebels, Barbara \& Dieter Wunderlich. 1994. Morphology feeds syntax: The case of particle verbs. Linguistics 32, 913-968.

Trotzke, Andreas. 2015. Rethinking syntactocentrism: Architectural issues and case studies at the syntax-pragmatics interface. Amsterdam: John Benjamins.

Trotzke, Andreas \& Stefano Quaglia. in press. Particle topicalization and German clause structure. The Journal of Comparative Germanic Linguistics.

Trotzke, Andreas, Stefano Quaglia \& Eva Wittenberg. 2015. Topicalization in German particle verb constructions: The role of semantic transparency. Linguistische Berichte 244, 407-424.

Webelhuth, Gert \& Farrell Ackerman. 1999. A lexical-functional analysis of predicate topicalization in German. American Journal of Germanic Linguistics and Literature 1, 1-61.

Wurmbrand, Susi. 2000. The structure(s) of particle verbs. Ms., McGill University. 
Xiang, Ming \& Gina R. Kuperberg. 2015. Reversing expectations during discourse comprehension. Language, Cognition, and Neuroscience 30, 648-672.

Zanuttini, Raffaella \& Paul Portner. 2003. Exclamative clauses: At the syntax-semantics interface. Language 79, 39-81.

Zeller, Jochen. 2001. Particle verbs and local domains. Amsterdam: John Benjamins.

Zeller, Jochen. 2003. Moved preverbs in German: Displaced or misplaced? In Geert Booij \& Ans van Kemenade (eds.), The yearbook of morphology, 179-212. Dordrecht: Kluwer.

Authors' addresses: (Trotzke)

Center for the Study of Language and Information, Stanford University,

210 Panama Street, Stanford, CA 94305-4115, USA

trotzke@stanford.edu

(Wittenberg)

Department of Linguistics, University of California, San Diego,

9500 Gilman Drive, La Jolla, CA 92093-0108, USA

ewittenberg@ucsd.edu 